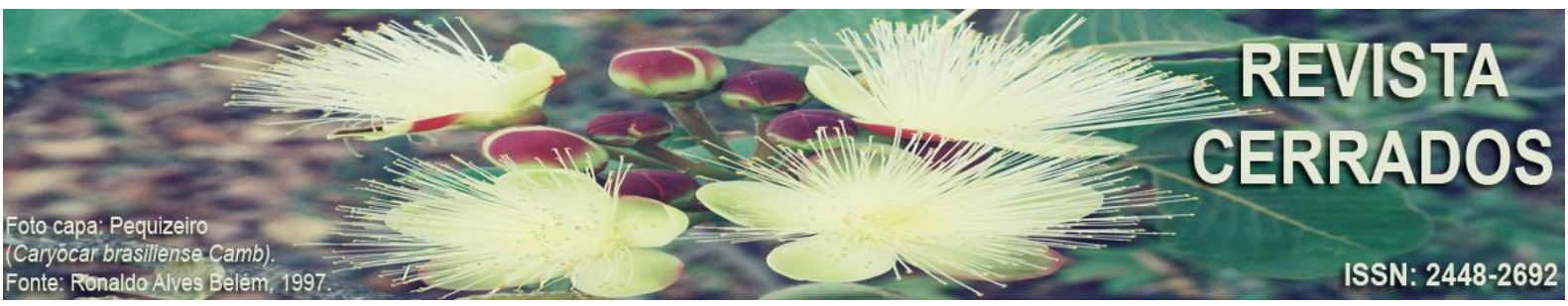

\title{
ESTUDO DE CASO DA DEGRADAÇÃO AMBIENTAL DO RIO GORUTUBA NO MUNICÍPIO DE FRANCISCO SÁ
}

\section{CASE STUDY OF THE GORUTUBA RIVER ENVIRONMENTAL DEGRADATION IN THE MUNICIPALITY OF FRANCISCO SÁ}

\section{ESTUDIO DE CASO DE LA DEGRADACIÓN DEL MEDIO AMBIENTE RÍO GORUTUBA EN EL MUNICIPIO DE FRANCISCO SA}

\author{
Maria Tereza Pereira dos Santos \\ Universidade Estadual de Montes Claros - UNIMONTES \\ E-mail: <mary_santos2014@hotmail.com.br>. \\ Expedito José Ferreira \\ Universidade Estadual de Montes Claros - UNIMONTES \\ E-mail: <expedito.jferreira@gmail.com>. \\ Maykon Fredson Freitas Ferreira \\ Universidade Estadual de Montes Claros - UNIMONTES \\ E-mail: <maykonfredson@gmail.com>.
}

\begin{abstract}
Resumo
O presente trabalho foi realizado na área compreendida pela bacia hidrográfica do Rio Gorutuba, no município de Francisco Sá - MG, e tem como objetivo analisar o estado de conservação e preservação do terço superior do seu curso d'água principal. Observações em nível local foram realizadas na sua nascente e ao longo do curso d'água até ao seu encontro com o Rio Água Quente, na divisa dos municípios de Francisco Sá, Janaúba e Riacho dos Machados. Os procedimentos metodológicos incluem pesquisas bibliográficas e documentais, observações de campo e elaboração de mapas que permitiram realizar as análises sobre a área estudada. A partir das análises observou-se que a área de estudo apresenta um nível elevado de poluição de suas águas e a ocorrência do processo de degradação da mata ciliar, presentes tanto na nascente e, também, ao longo do curso d'água, em ambas as margens. Observou-se, ainda, a necessidade de adoção de medidas adequadas a serem desenvolvidas pelo poder público, com a participação massiva da população, além de campanhas de educação ambiental sobre a necessidade de preservação e sobre a redução dos impactos ambientais negativos presentes na área estudada.
\end{abstract}


Palavras-chave: Bacia hidrográfica; Degradação Ambiental; Rio Gorutuba.

\begin{abstract}
This work was carried out in the area of the Gorutuba River basin, in the municipality of Francisco Sá - MG, and aims to analyze the state of conservation and preservation of the upper third of its main watercourse. Observations at the local level were carried out at its source and along the water course until its encounter with the Água Quente River, on the border of the municipalities of Francisco Sá, Janaúba and Riacho dos Machados. The methodological procedures include bibliographical and documentary research, field observations and the elaboration of maps that allowed to carry out the analyzes on the studied area. From the analyzes, it was observed that the study area presents a high level of pollution of its waters and the occurrence of the process of degradation of the ciliary forest, present both in the spring and also along the water course, in both the margins. It was also observed the need to adopt adequate measures to be developed by the public power, with the massive participation of the population, as well as environmental education campaigns on the need for preservation and on the reduction of negative environmental impacts present in the studied area.
\end{abstract}

Keywords: Hydrographic basin. Ambiental degradation. Gorutuba River.

\title{
Resumem
}

Este trabajo se llevó a cabo en el área cubierta por la cuenca del río Gorutuba en el municipio de Francisco Sá - MG. Se hicieron observaciones locales en su origen, pasando por diferentes puntos para el encuentro del río Gorutuba con lo Rio Àgua Quente en la frontera de los municipios de Francisco Sá, Janaúba y Riacho dos Machados. El objetivo de este estudio fue analizar el estado de conservación y preservación del tercio superior del curso de agua principal, situada en el municipio de Francisco Sá. Los procedimientos metodológicos incluyen fondos bibliográficos y documentales de investigación, observaciones de campo y preparación de mapas, que han permitido el análisis de la zona de estudio. A partir del análisis, se observó que el área de estudio tiene un alto nivel de contaminación de sus aguas y la aparición del proceso de degradación de la vegetación de ribera presente en el este ya lo largo de la orilla del río. Esta vez, se concluye que es necesario adoptar medidas apropiadas desarrolladas en conjunto con la población y las autoridades, así como campañas de educación ambiental dirigidas a concienciar y reducir los impactos ambientales negativos presentes en el área de estudio.

Palabras clave: Cuenca hidrográfica; La degradación ambiental; Rio Gorutuba.

\section{INTRODUÇÃO}

A água é um recurso indispensável para a vida, visto que constitui a base de todos os processos bioquímicos e fisiológicos dos organismos vivos (CHAVES, 2009). Segundo a 
UNESCO, as águas doces representam apenas $2,7 \%$ da disponibilidade hídrica total do planeta, que é de 1.380 milhões de $\mathrm{km}^{3}$. Porém, a maior parte dessa água doce encontra-se em estado sólido nas geleiras, icebergs e calotas polares, onde a água doce disponível para consumo humano (água presente em rios, lagos e aquíferos de menor profundidade) representa menos de $1 \%$ da disponibilidade hídrica total (CHAVES, 2009). Neste sentido, a preservação, conservação e manutenção das fontes de recursos hídricos são fundamentais à sobrevivência dos seres vivos. Apesar de a água ser um elemento renovável, há duas grandes problemáticas a serem analisadas: a distribuição no espaço geográfico e o uso inadequado, que intensificou com o adensamento populacional e a revolução agrícola (MENDONÇA; LEITÂO, 2008).

A crise ambiental atual é resultante da relação humana com os recursos naturais, que sempre teve em mente que esses recursos não seriam finitos, e daí a ideia de usá-los de forma desenfreada, visando à obtenção apenas do acúmulo de riquezas para o bem estar humano, sem considerar o meio ambiente. Para Mendonça e Leitão (2008, p. 153), "mesmo dependendo essencialmente da água para sua vida, os homens e as sociedades humanas desenvolveram uma relação fortemente negativa com este elemento natural, resultando na preocupante degradação do mesmo". E apesar da divulgação acerca da necessidade de uma melhor gestão dos recursos hídricos em virtude de sua possível escassez mundial, a sociedade caminha em direção oposta, com o lançamento de resíduos domésticos e/ou industriais nos corpos d'água, assim como a sua destinação para escoar minérios, a destruição das matas ciliares, e o próprio desperdício desse recurso devido à má gestão em escalas cada vez maiores (MENDONÇA; LEITÃO 2008; CHAVES, 2009).

A análise do estado de degradação de uma bacia hidrográfica, necessariamente, requer conhecimentos sobre o comportamento da mesma, no intuito de compreender a sua importância no contexto ambiental e qual relação existente com o meio social para assim poder desenvolver alternativas e técnicas de preservação e conservação da mesma (SANTOS et al., 2007).Atualmente as bacias hidrográficas têm sido alvo de uma série interferências antrópicas que comprometem a sua biodiversidade as quais, dentre as principais, citam-se os desmatamentos em áreas de nascentes, a ausência de vegetação ciliar, as queimadas, a presença de corpos estranhos e lançamentos de dejetos nos cursos d'águas, a contaminação por produtos tóxicos agrícolas, entre outros, que degradam e comprometem a vida da bacia hidrográfica (ORTEGA, 2011). 
A bacia hidrográfica pode ser entendida como uma rede de drenagem de vários rios. Lima (2008) pontua que bacia hidrográfica é toda a área de captação natural da água da chuva que proporciona escoamento superficial para o canal principal e seus tributários. Ainda de acordo o Lima (2008), o limite superior da bacia é o divisor de águas (divisor topográfico) e a delimitação inferior é à saída da bacia (confluência ou exutório). Assim, os limites da bacia hidrográfica são definidos pelo relevo, considerando-se como divisores de água os terrenos mais elevados. E, desta feita, a bacia hidrográfica pode apresentar diferentes formas, variando de estreita e alongada, a larga e curta, de acordo com o relevo de onde se encontra (LINO e DIAS, 2005).

Devido às suas características, e pelo fato de associar os fatores físicos à quantidade e qualidade de água direcionada ao corpo hídrico, a bacia hidrográfica é considerada como principal unidade de gerenciamento e planejamento dos recursos naturais (SOUZA; SILVA; DIAS, 2012). Neste sentido, a gestão de Bacias Hidrográficas é fundamental para a análise do potencial oferecido pela mesma e para a formulação de técnicas que proporcionem o desenvolvimento de uma área sem que haja prejuízos ao meio ambiente (PIRES, SANTOS E DEL PRETTE, 2002). Ainda segundo Pires, Santos e Del Prette (2002), o gerenciamento de bacias deve ser interligado ao progresso desenvolvimentista de maneira a minimizar os impactos ambientas na área de ação. Os autores citados destacam que o Gerenciamento de Bacia Hidrográfica torna-se então o instrumento orientador das ações do poder público e da sociedade no controle do uso dos recursos ambientais na área de abrangência de uma bacia hidrográfica, com vistas ao desenvolvimento sustentável (MENDES, 2006).

Atualmente, os ambientes aquáticos são utilizados em todo mundo com distintas finalidades, destacando-se o abastecimento de água, a geração de energia, a irrigação, a navegação, a agricultura e a harmonia paisagística (MORAES; JORDÃO, 2002). Com isso surgem diversos problemas relacionados ao uso e gestão dos recursos hídricos, principalmente no que concerne ao desperdício e contaminação da água potável. Quando os rios adentram as cidades, são confinados para darem espaço para o trânsito e sofrem o lançamento de despejos e dejetos, causando a poluição dos mesmos, resultando em mau cheiro, proliferação de vetores causadores de doenças e enchentes, resultando em prejuízo para o meio natural e para a própria humanidade (MORAES; JORDÃO, 2002). 
Mendes (2006) ressalta que o impacto decorrente da alteração do uso do solo reflete em todos os componentes do ciclo hidrológico, como o escoamento superficial, a recarga dos aquíferos, a qualidade da água e o transporte de sedimentos. Neste sentido, Braga et al (2006, p.150) afirma que: “A informação sobre a qualidade da água é necessária para que se conheça a situação dos corpos hídricos com relação aos impactos antrópicos na bacia hidrográfica e é essencial para que se planeje sua ocupação e seja exercido o necessário controle dos impactos." Dessa forma, a determinação da qualidade da água é importante para sabermos se a água é potável ou não, tendo em vista que a água potável é essencial em nossas vidas, e que esse recurso é de fácil contaminação, o que o torna frágil e com grandes chances de se tornar escasso (MACHADO, FERREIRA E RITTER, 2004).

O estado de degradação em que se encontram nossas bacias hidrográficas, de acordo com Pires, Santos e Del Prette (2002), está intimamente relacionado à nossa falta de comprometimento e de políticas públicas de sensibilização da população sobre a importância e a forma sustentável de se apropriar dos recursos naturais, para que não gerem prejuízos econômicos e sociais e sim tragam benefícios para a sociedade e para a própria bacia hidrográfica.

Considerando que a água é um dos elementos essências para a vida no planeta Terra e que mesmo assim a mesma é alvo de vários tipos de contaminação, tornando-a imprópria para o consumo humano, se faz necessário uma boa gestão desse recurso. E, assim sendo, a bacia hidrográfica, principal fonte de água potável, é a unidade mais apropriada para o estudo qualitativo e quantitativo do recurso água e dos fluxos de sedimento e nutrientes (PIRES, SANTOS E DEL PRETTE, 2002).

Ainda discutindo a questão da bacia hidrográfica como unidade de gestão ambiental, Silva, Schulz e Camargo (2003, 2004) consideram que as características naturais presentes nas bacias hidrográficas facilitam as atividades de gerencia do uso e conservação dos recursos naturais, principalmente nas situações atuais onde ocorre grande pressão sobre o ambiente em decorrência do crescimento demográfico e do desenvolvimento. Pires, Santos e Del Prette (2002) ressaltam que a adoção das bacias hidrográficas como unidade de planejamento para a conservação de recursos naturais está atrelada à possibilidade e facilidade de avaliar, em uma determinada área geográfica, o seu potencial de desenvolvimento e a sua produtividade biológica, e, a partir de então, determinar as melhores formas de aproveitamento dos mesmos, causando o mínimo impacto ambiental. 
De acordo com o exposto, é possível ter noção da importância do gerenciamento das bacias hidrográficas para a preservação e conservação dos recursos naturais, porém, para esse gerenciamento alcançar seus objetivos almejados, deve haver uma interação entre os agentes econômicos, sociais e naturais, ou seja, uma integração de planejamento e administração (SETTI, et al 2000).

A área objeto deste trabalho é a bacia hidrográfica do Rio Gorutuba, inserida na mesorregião Norte de Minas, integrante, por sua vez, da bacia do Rio Verde Grande. Especificamente, os estudos foram direcionados para a porção da área da bacia hidrográfica que compreende o terço superior do Rio Gorutuba, com observações e análises realizadas a partir da nascente passando pelo distrito de Catuni até a confluência com o Rio Água Quente na divisa do município de Francisco Sá com Janaúba e Riacho dos Machados.

A bacia hidrográfica do Rio Gorutuba possui uma área de $9.862,7 \mathrm{Km}^{2}$ e abrange quatorze municípios, a saber: Francisco Sá, Janaúba, Riacho dos Machados, Serranópolis de Minas, Nova Porteirinha, Porteirinha, Pai Pedro, Mato Verde, Catuti, Monte Azul, Jaíba, Verdelândia, Gameleiras e Mamonas. O principal corpo d'água que drena as águas que afluem na bacia é o Rio Gorutuba, tem a sua nascente no município de Francisco Sá - MG, especificamente nas coordenadas geodésicas à $16^{\circ} 24.999^{\prime} \mathrm{S}$ e $43^{\circ} 21.938^{\prime} \mathrm{W}$ e a $1.090 \mathrm{~m}$ de altitude. Encontra-se e a uma distância aproximadamente de $1 \mathrm{~km}$ da rodovia BR 251, a 29 $\mathrm{km}$ do Distrito de Catuni, e aproximadamente a $24 \mathrm{~km}$ da sede do município.

O Rio Gorutuba percorre $245 \mathrm{~km}$ desde a sua nascente até a foz, passando pelos municípios de Francisco Sá, Janaúba, Porteirinha, Nova Porteirinha, Gameleiras e Jaíba, onde deságua no rio Verde Grande, como se acha visualizado na Figura 1.

Quanto às características físicas da área de estudo, a bacia do Rio-Gorutuba encontra se localizada entre os paralelos $14^{\circ} 50^{\prime}$ e $16^{\circ} 10^{\prime}$ de latitude Sul e os meridianos $43^{\circ}$ $05^{\prime}$ e $43^{\circ} 40^{\prime}$ de longitude oeste. Localiza-se em uma área de regime hidroclimatológico irregular, com períodos de estiagem prolongados, com inverno seco e verão chuvoso, sendo que esse período chuvoso concentra-se basicamente entre os meses de novembro a abril, o que caracteriza o tipo climático Aw, de acordo com a classificação de Köppen (NUNES, 2003). 
Figura 01- Mapa de localização da bacia hidrográfica do rio Gorutuba.

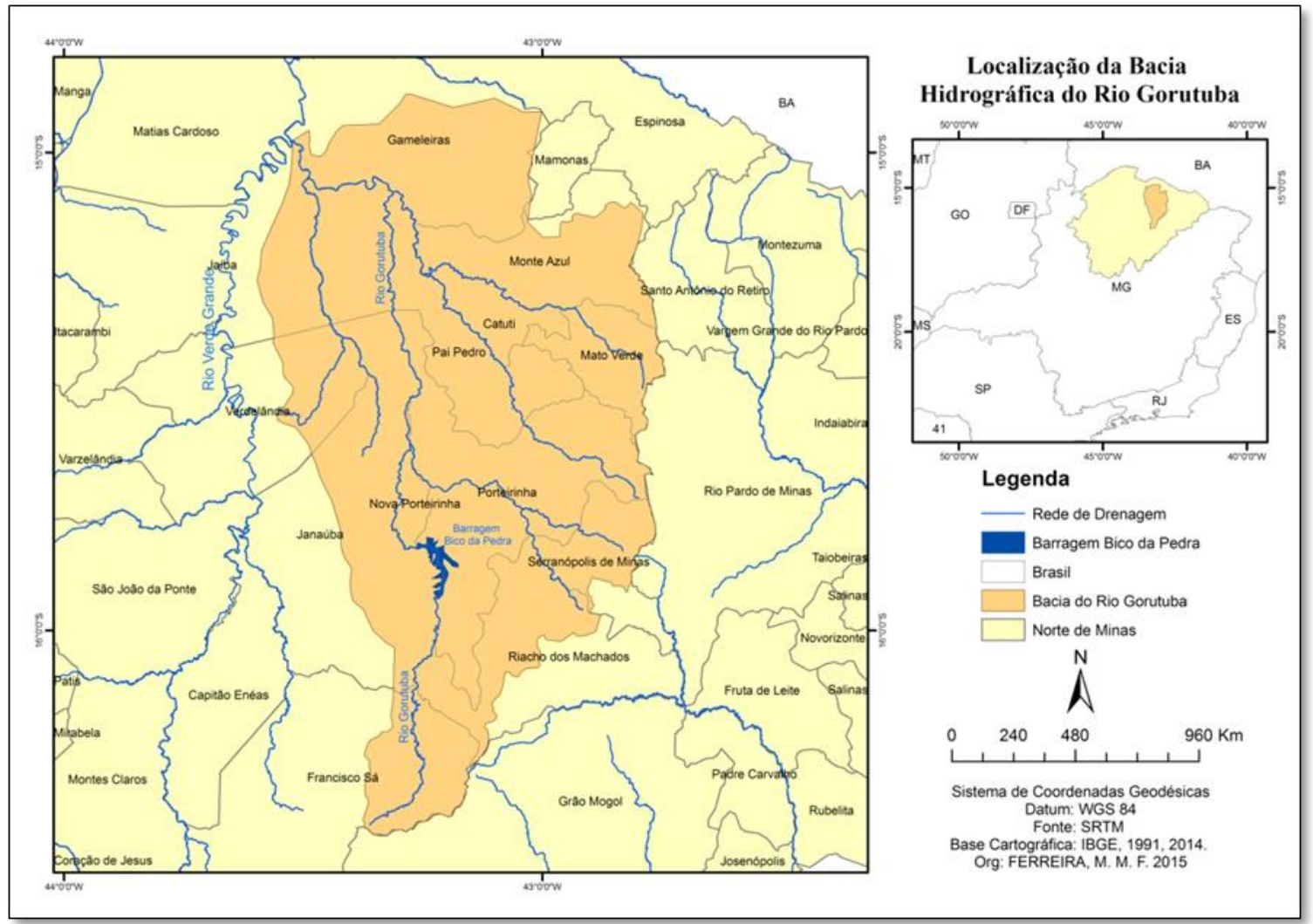

Org.: FERREIRA, M. F. F., 2015

Para a realização deste trabalho, utilizou procedimentos metodológicos já caracterizados por diversos estudiosos, que tem como base a realização de pesquisas bibliográficas e observações locais da área de trabalho. Assim, foram realizadas consultas bibliográficas em livros, em documentações e artigos técnicos, em sites especializados na internet, entre outros. Em complemento, foram realizadas várias visitas na área de estudo, com instrumentais adequados para possibilitar a obtenção das coordenadas geográficas e de registros fotográficos dos locais percorridos. Para a elaboração dos mapas utilizou-se o software ARCGIS 9.3.3.

A pesquisa bibliográfica teve o objetivo de conceituar e discutir aspectos sobre o tema do trabalho visando melhor entendimento do assunto, além de propiciar bases para a realização dos trabalhos de campo. Os trabalhos de campo foram realizados pela autora do trabalho, em pontos distintos do Rio Gorutuba, dentro do trecho que vai da nascente até o encontro do Rio Gorutuba com o Rio Água Quente. Nesse trajeto priorizaram-se alguns pontos de trabalho, como as nascentes do Rio Gorutuba e do rio Ribeirão, o trecho do Rio Gorutuba que passa pelo distrito de Catuni, e alguns outros pontos abaixo do distrito, como o 
encontro do rio Ribeirão com o Gorutuba, a cachoeira de Dete e o encontro com o Rio Água Quente, além de observações em trechos dos Rios Água Quente e Ribeirão. A Figura 2 mostra todos os pontos onde os trabalhos foram realizados no interior da bacia hidrográfica estudada.

Figura 02 - Mapa de localização dos pontos visitados na área de estudo.

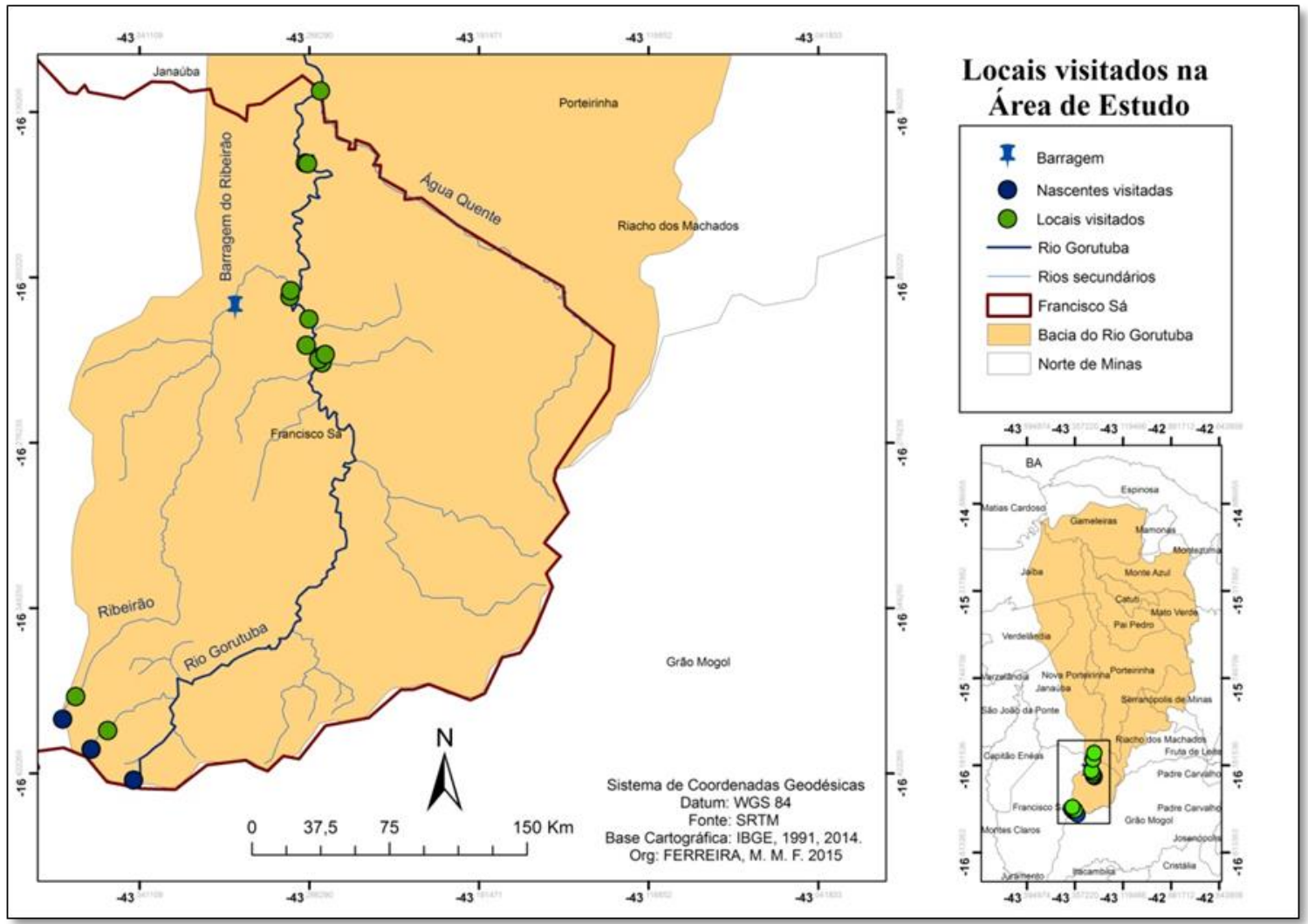

Org.: FERREIRA, M. F. F., 2015

Essas observações foram realizadas em etapas distintas, onde a primeira etapa do trabalho foi realizada no período de estiagem, na nascente e no trecho que passa no distrito de Catuni, para observar o comportamento do rio. Na segunda etapa do trabalho realizou-se visita de campo no período da cheias do rio, no mesmo percurso acima citado, também, com o mesmo objetivo de observar o comportamento do rio. Utilizou-se o Sistema de Posicionamento Global (GPS) para registrar os pontos de coordenadas da nascente do Gorutuba, dos locais de passagem do rio em Catuni, bem como em outros pontos do rio e de seus afluentes. Nessa etapa também utilizou se câmera fotográfica para registrar imagens das paisagens observadas em campo. 
As visitas de campo para observações locais ocorreram no período de estiagem, em outubro de 2014, e no período chuvoso, compreendido entre dezembro de 2014 e janeiro de 2015.

Após a realização de trabalhos de campo utilizou-se a cartografia, para a elaboração de mapas, no intuito de identificar e espacializar os pontos visitados em campo, e também para delimitar a área de abrangência da bacia.

\section{RESULTADOS E DISCUSSÃO}

As observações realizadas em nível de campo mostram que a nascente do Rio Gorutuba se encontra em bom estado de preservação, muito provavelmente, em face da sua localização isolada e na porção mais baixa do vale e, ainda, por possuir uma mata fechada ao seu redor, o que dificulta o acesso ao local. Como se visualiza na Figura 3, no entorno da nascente existe bastante matéria orgânica, originada da mata fechada que a circunda como se pode observar pela Figura 4. Isto contribui, sem dúvida, para o processo de infiltração de água no solo e abastecimento do lençol freático, conforme mencionado por Castro, Mello e Poester (2012. p.7), que "as matas ciliares influenciam na qualidade da água, na regulação do regime hídrico, na estabilização de margens do rio, na redução do assoreamento da calha [...]”.

\section{Figura 03 - Nascente do Rio Gorutuba.}

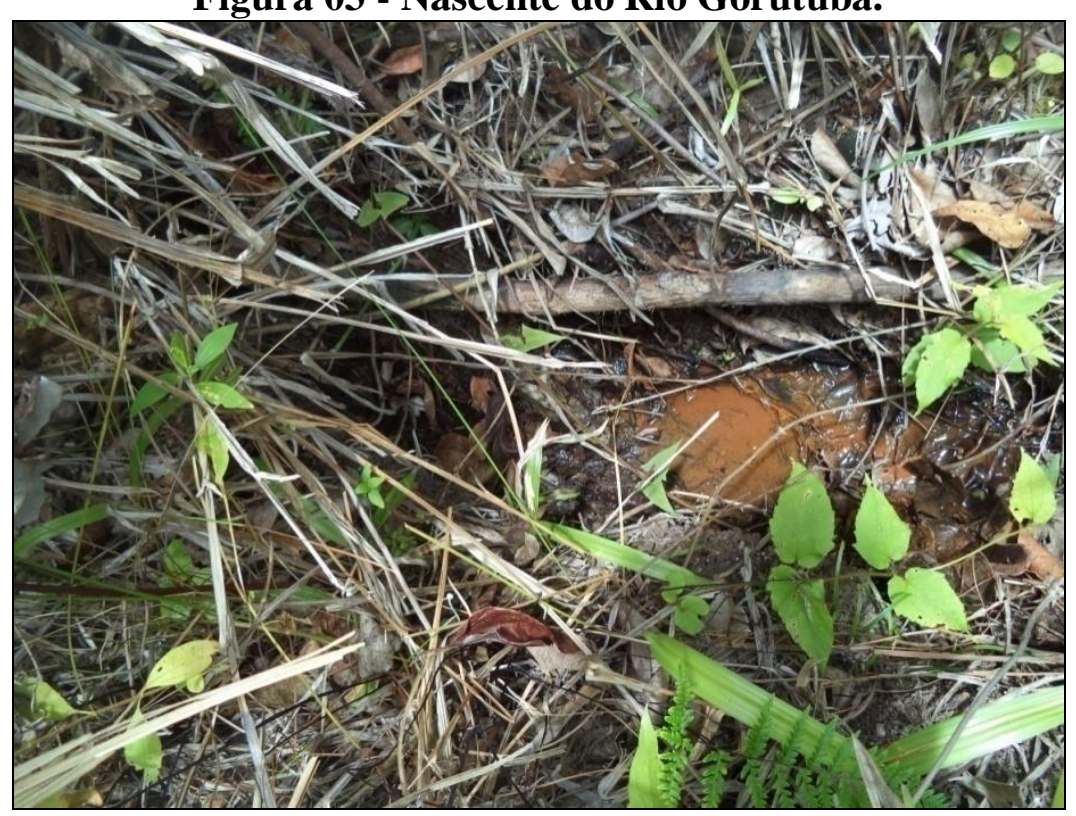

Autor: SANTOS, M. T. P. 26 de dezembro de 2014. 
Figura 04 - Mata ao entorno da nascente.

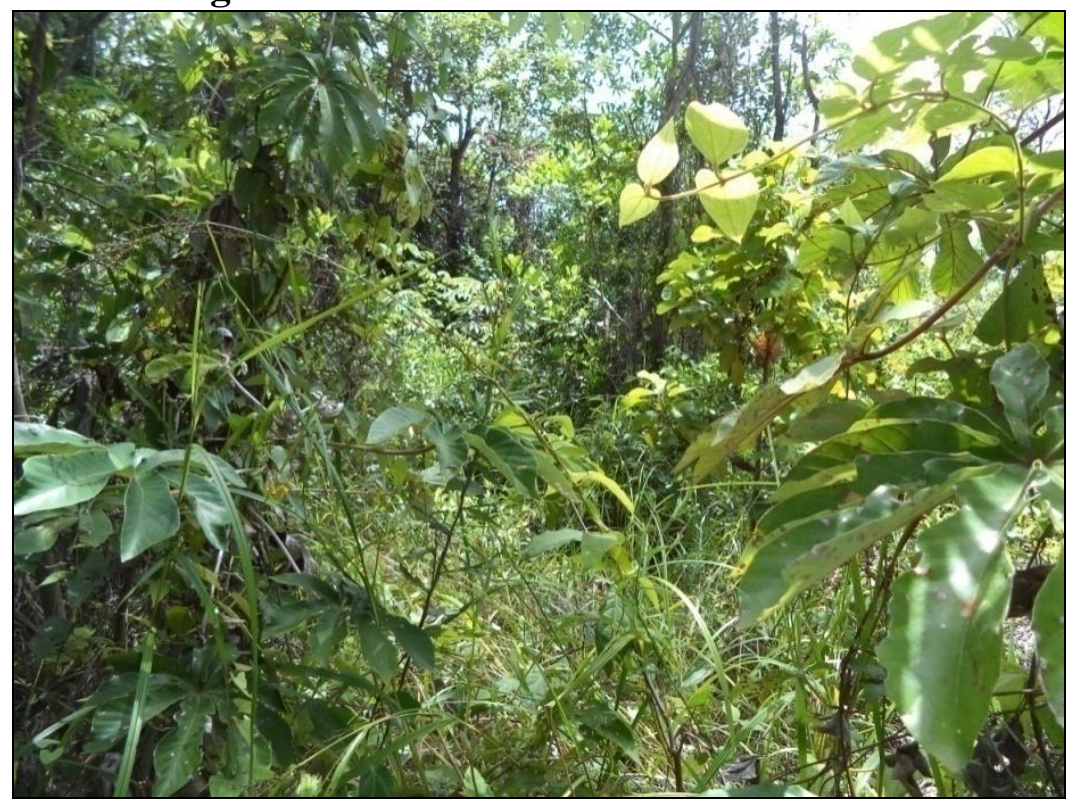

Autor: SANTOS, M. T. P. 26 de dezembro de 2014.

Em que pese o isolamento e as dificuldades de acesso ao local, observou-se, por sua vez, que a ação antrópica já se faz presente nas proximidades da nascente, onde se nota sinais de queimada, que não se sabe a causa, como mostra a Figura 5, e algumas áreas desmatadas, visualizadas pela Figura 6, resultado tão somente da inconsequência do homem, que não pensa no resultado de seus atos.

Figura 05 - Queimada na área da nascente.

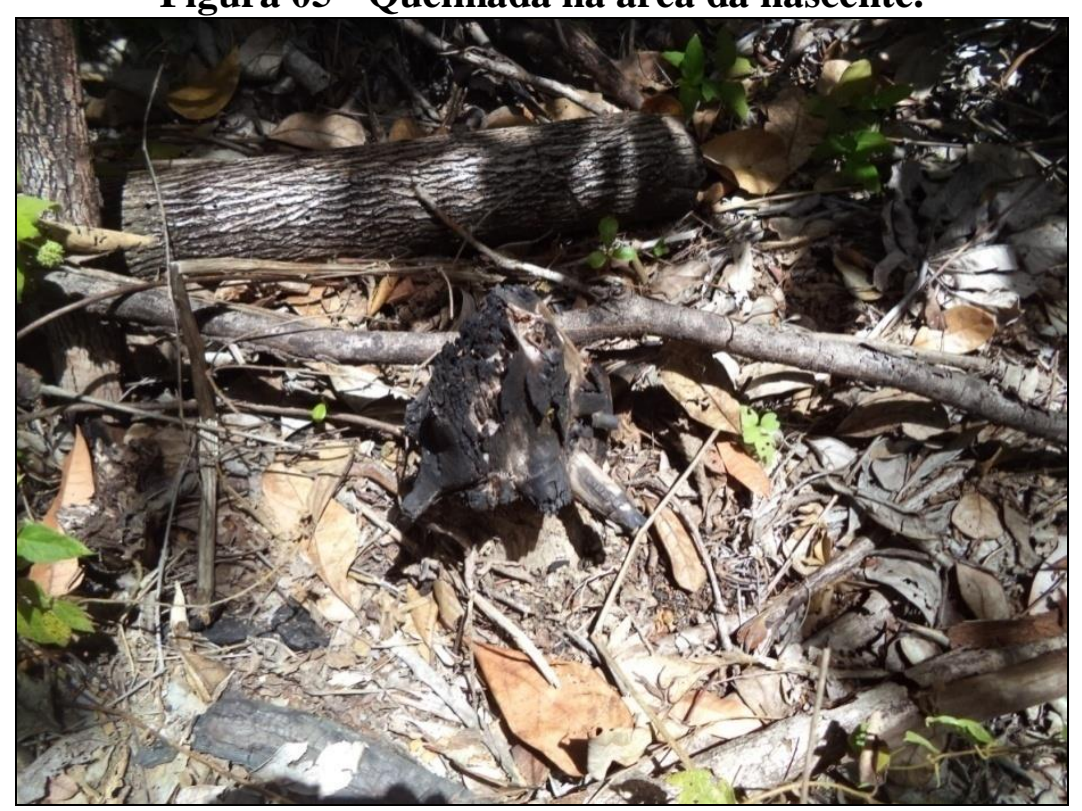

Autor: SANTOS, M. T. P. 26 de dezembro de 2014. 


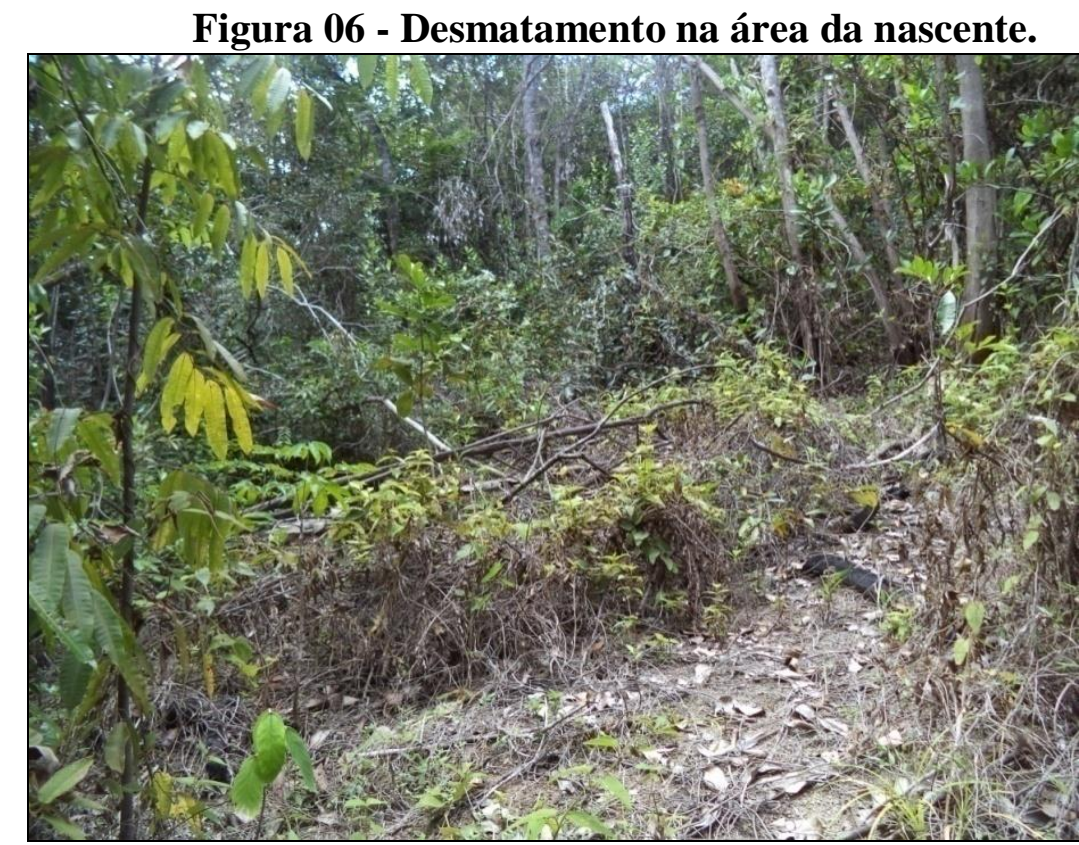

Autor: SANTOS, M. T. P. 26 de dezembro de 2014.

Ainda na área da nascente, mais especificamente na área de recarga, a uma distância aproximada de $1.800 \mathrm{~m}$, encontra-se uma plantação de eucalipto que foi estabelecida há mais ou menos 8 anos, com a retirada a vegetação natural, conforme apresentado na Figura 7.

Figura 07 - Plantação de Eucaliptos próximo a nascente.

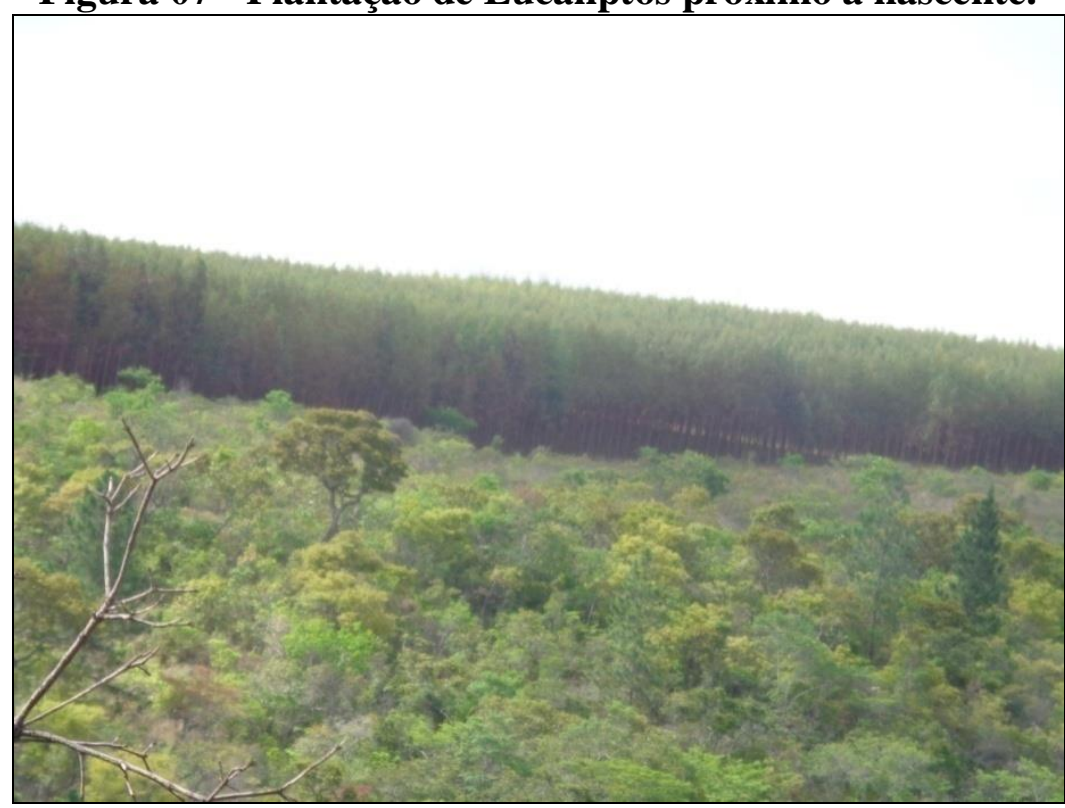

Autor: SANTOS, M. T. P. 26 de dezembro de 2014.

A partir da nascente até o distrito de Catuni, o Rio Gorutuba recebe alguns tributários como o Peixe Manso e o Rio da Tolda. Nesse percurso o mesmo é utilizado por 
proprietários de terras que moram nas suas margens que utilizam de suas águas, captadas por bombeamento, para diversas finalidades, como consumo doméstico, irrigação de plantações e para saciar a sede de animais.

Em sua passagem pelo distrito de Catuni, o Rio possibilita diferentes formas de sua utilização, às quais se destacam o turismo, a irrigação de pequenas lavouras e a dessedentação animal. Salienta-se, ainda, quede forma inadequada a população ainda utiliza do rio para lavagem de roupas e de veículos, além de ocorrer lançamento de esgotos diretos ao rio. Essas práticas realizadas pelos habitantes do distrito geram consequências, como o desmatamento da mata ciliar, que acarreta a erosão das encostas e, por conseguinte o assoreamento do rio; a poluição das águas, causada principalmente pelo lançamento de esgoto; e também a inconsequência de turistas que buscam somente o lazer às margens do rio, sem se preocupar com o lixo que deixam espalhados por toda parte, como dentro e nas margens do rio. A Figura 8 mostra rastros de poluição no rio.

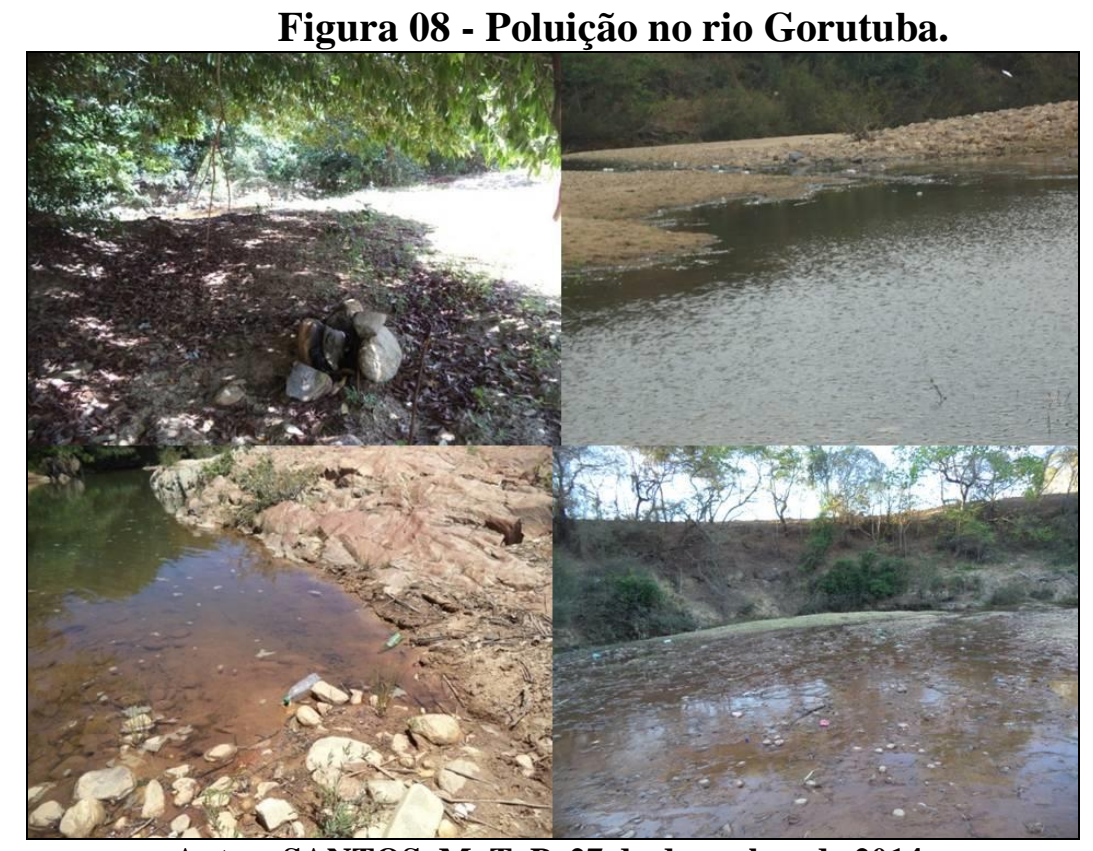

Autor: SANTOS, M. T. P. 27 de dezembro de 2014.

O desmatamento nas margens do Rio Gorutuba geralmente é feito em função da necessidade de abrir novas áreas para pastagens, com fácil acesso do gado ao rio para saciar a sua sede. Entretanto, o que se observa é que a prática do desmatamento na região é realizada junto com as queimadas e esse procedimento tem acarretado a erosão das encostas que por sua vez causa o assoreamento do Rio. De acordo com Oliveira e Silva (1994), um fator que 
agrava a erosão dos solos é a queimada, muito utilizada na agricultura com finalidade de expandir a área cultivada e também de adubação do solo, pois se acredita que a cinza proveniente da combustão da vegetação é um adubo para a terra, causando, assim, a constante abertura de novas áreas destinadas à agricultura e a inaptidão dos solos.

A erosão do solo, como já citado, se dá com a retirada total da vegetação, deixando-o exposto. Este solo exposto fica vulnerável ao processo de erosão, o que acarreta no assoreamento dos leitos dos rios, pois, com as chuvas, esses solos, principalmente os localizados nas encostas, são carreados mais facilmente para dentro do leito pluvial (ARAUJO; ALMEIDA; GUERRA, 2005). O assoreamento nos leitos dos rios, dentre outros problemas, causa alterações no regime das cheias, mudanças no leito do rio e redução da vazão de rio, além de gerarem o desconforto para a população ribeirinha, devido à área de abrangência das enchentes que podem atingir suas moradias, causando perdas de bens materiais (ARAUJO; ALMEIDA; GUERRA, 2005).

De acordo com o exposto acima, entende-se que os processos de erosão e assoreamento estão totalmente relacionados ao desmatamento e às queimadas, gerando assim vários problemas de ordem econômica, social e ambiental. As principais causas relacionadas à erosão e ao assoreamento estão relacionadas às novas áreas de práticas agropecuárias, a expansão de centros urbanos e também a abertura de áreas para a mineração (PIRES, SANTOS E DEL PRETTE, 2002).

É possível observar na Figura 9 que praticamente toda a vegetação natural da margem direita do rio foi retirada para dar lugar a áreas de pastagens.

Outra situação observada no Rio Gorutuba, dentro de distrito de Catuni, é que o assoreamento do seu leito ocorre em praticamente toda sua extensão e que, devido a isso, aliado à falta de chuva na região, o rio encontra-se com pouca água, em uma época em que era para estar com um volume bem maior, como habitualmente acontece. Pode-se afirmar, desta feita, que a vazão do rio no período da seca no ano de 2014, não se diferenciou muito do período chuvoso. E esta situação, como não poderia deixar de ser, foi o período de menor ocorrência de chuvas na região, como se pode observar na Figura 10. 
Figura 09 - Desmatamento nas margens do rio.

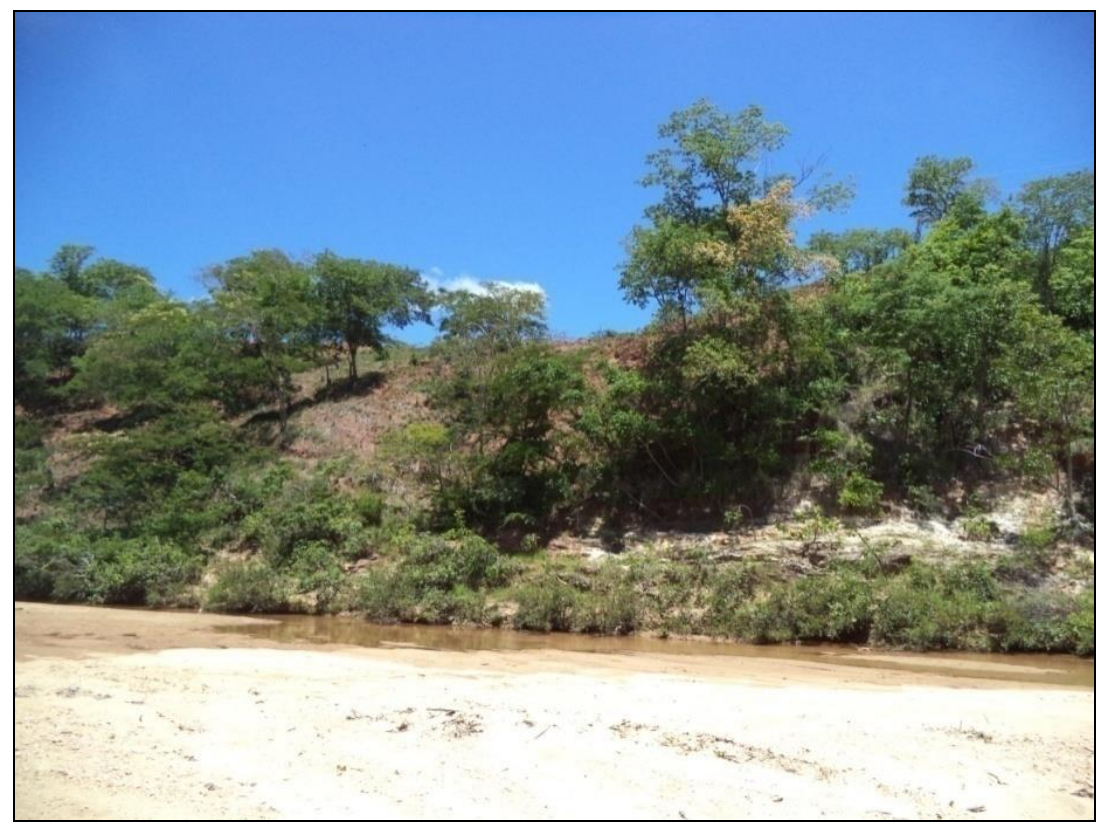

Autor: SANTOS, M. T. P. 26 de dezembro de 2014.

Figura 10 - Vazão do rio no período seco e chuvoso.

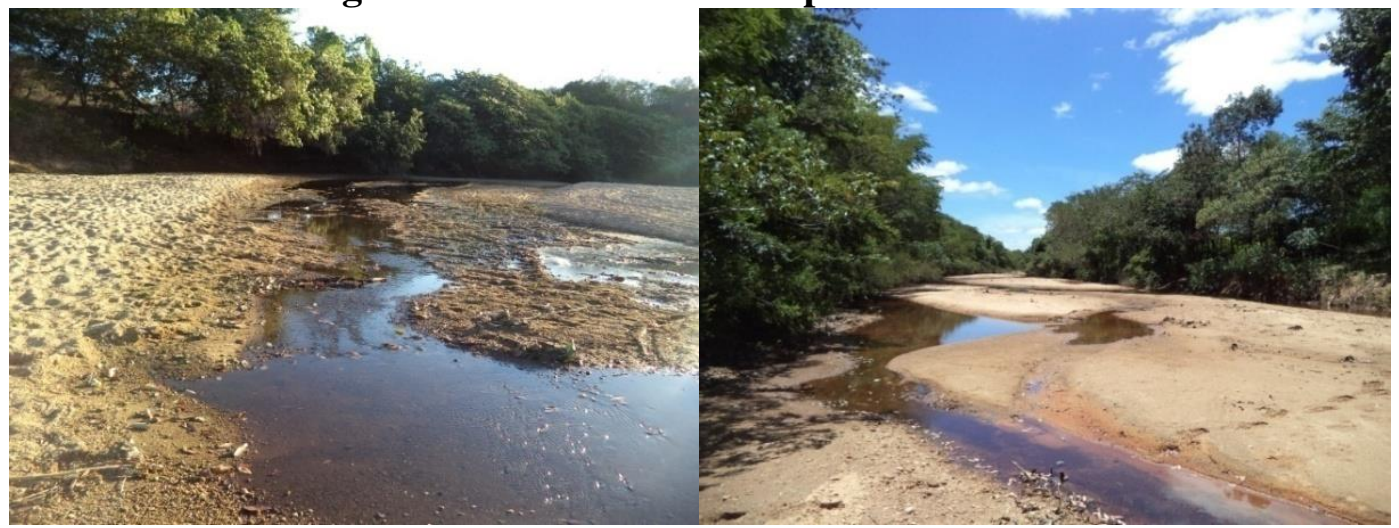

10a.- Período de estiagem.

10b. - Período chuvoso.

Autor: SANTOS, M. T. P. 04 de outubro de 2014. Autor: SANTOS, M. T. P. 26 de dezembro de 2014.

A Figura 10a mostra a vazão do Rio no período de estiagem, em outubro de 2014, cuja duração se estendeu até final de outubro. A Figura 10b mostra a vazão do rio no final do mês de dezembro, período considerado chuvoso. Por observação da autora deste trabalho, concluiu-se que o índice pluviométrico na região foi muito baixo, não sendo suficiente para aumentar o volume da vazão do rio, mesmo ocorrendo duas cheias.

Em outro ponto do Rio Gorutuba, em Catuni, encontra-se o lançamento de esgoto direto no seu curso sem nenhum tipo de tratamento, o que deixa a água imprópria para o consumo da população, que depende basicamente da água do rio para o abastecimento 
doméstico (Figura 11). Quanto à contaminação das águas presentes nas bacias hidrográficas, Pereira (2004) considera que, "a água pode ter sua qualidade afetada pelas mais diversas atividades do homem, sejam elas domésticas, comerciais ou industriais. Cada uma dessas atividades gera poluentes característicos que têm uma determinada implicação na qualidade do corpo receptor". Essa contaminação das águas gera vários problemas, devido à perda de sua qualidade que afeta desde a vida aquática, até a vida humana (PIRES, SANTOS E DEL PRETTE 2002).

Figura 11 - Esgoto lançado no Gorutuba.

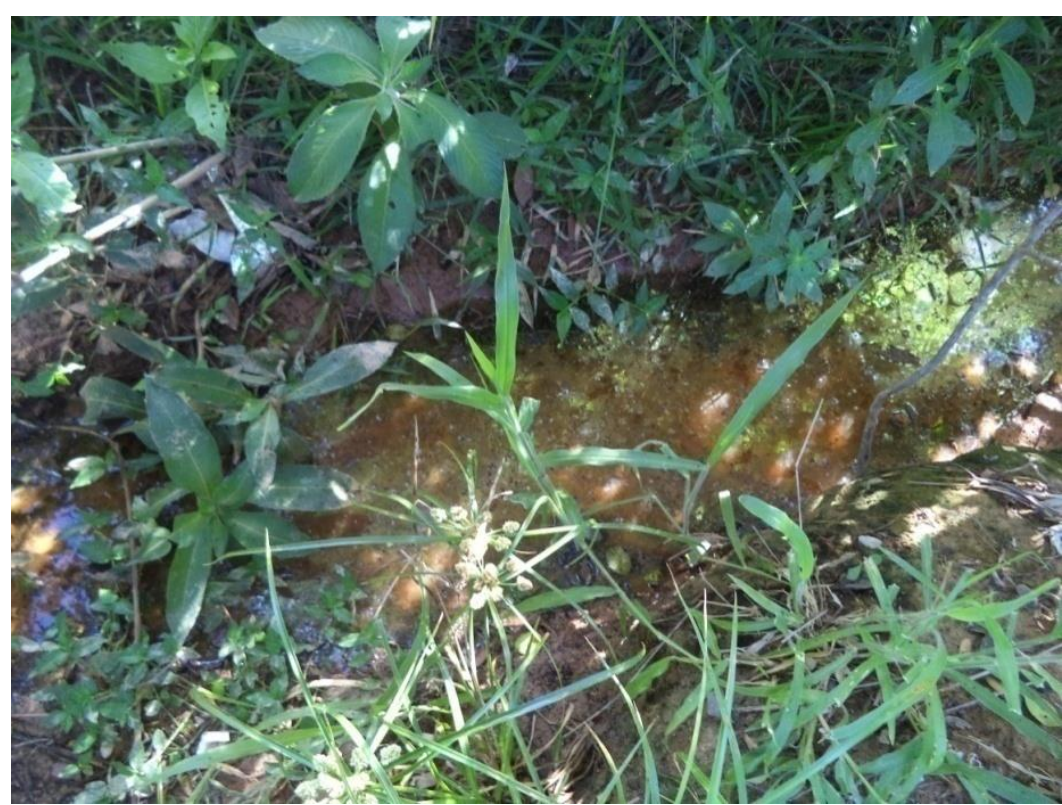

Autor: SANTOS, M. T. P. 30 de dezembro de 2014.

Abaixo do distrito de Catuni, o Rio Gorutuba recebe como afluente da margem esquerda, o rio Ribeirão, nos pontos $16^{\circ} 12.550 S^{\prime}$ e $43^{\circ} 16.466^{\prime} \mathrm{W}$, como se observa na Figura 12. Após o encontro dos dois rios verifica-se um aumento da vazão do rio Gorutuba, justamente pela contribuição do Ribeirão, e a partir dessa confluência, o rio Gorutuba percorre seu curso com maior vazão, diminuindo assim os pontos de intermitência.

Nos pontos $16^{\circ} 07.262^{\prime} \mathrm{S}$ e $43^{\circ} 15.680^{\prime} \mathrm{W}$ o rio Gorutuba se encontra com um de seus afluentes da margem direita, o chamado rio Água Quente. E neste ponto é onde ocorre a divisão dos municípios de Francisco Sá e Riachos dos Machados e também dos municípios de Francisco Sá e Janaúba. A Figura 13mostra o encontro destes rios. 


\section{Figura 12 - Encontro do Gorutuba com o rio Ribeirão.}

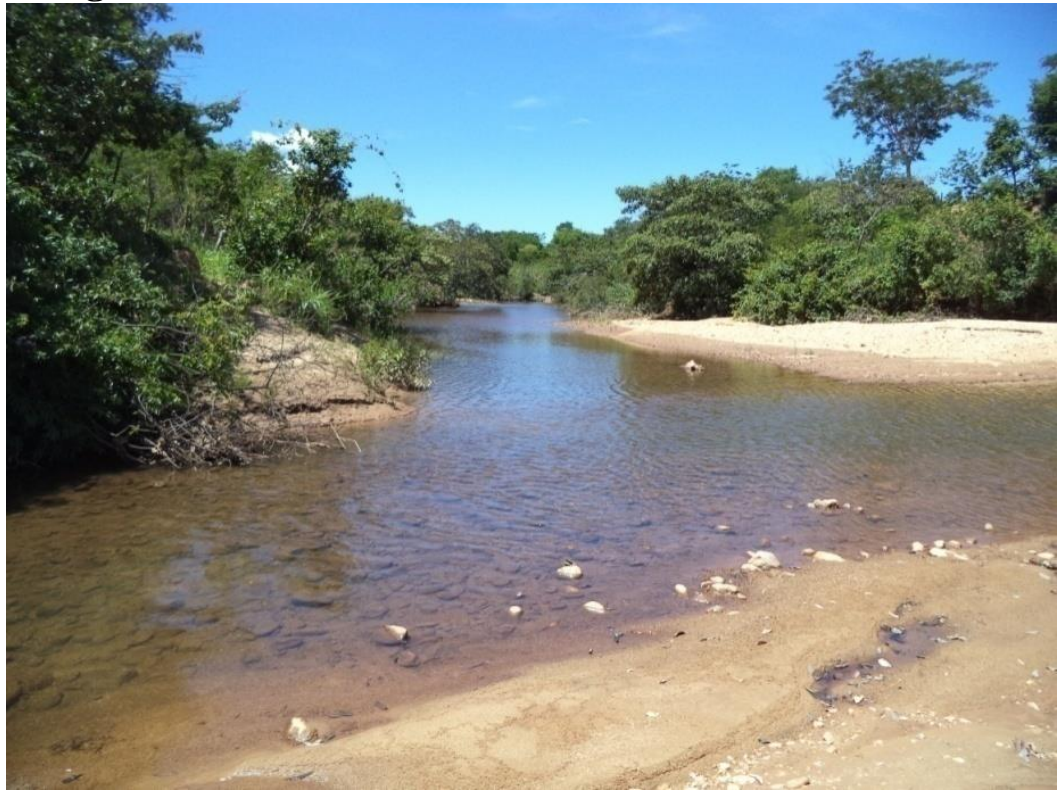

Autor: SANTOS, M. T. P. 27 de dezembro de 2014.

Figura 13 - Encontro do Gorutuba com o rio Água Quente.

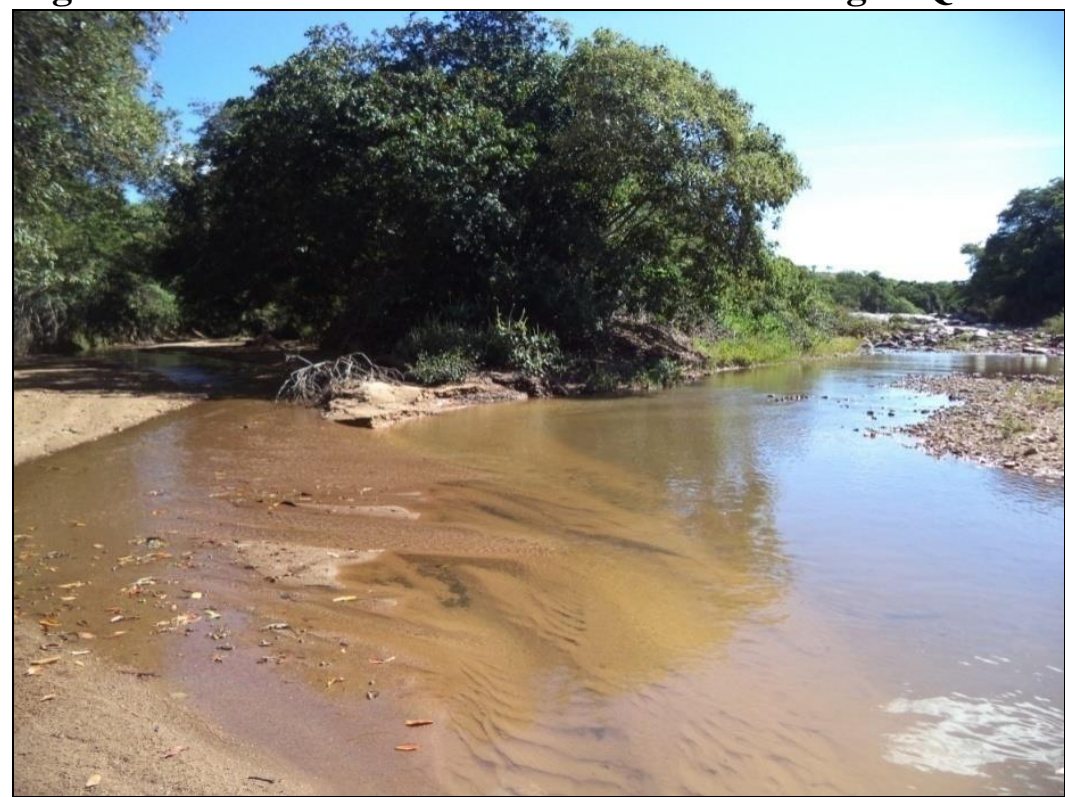

Autor: SANTOS, M. T. P. 27 de dezembro de 2014.

A partir do encontro com o Rio Água Quente, o Rio Gorutuba segue seu curso até a barragem "Bico da Pedra" localizada no município de Janaúba, que entre outras funções abastece o projeto de Irrigação do Gorutuba, e, após a barragem, passa por outros municípios norte mineiro até encontrar com o rio Verde Grande no município de Jaíba. 


\section{CONSIDERAÇÕES FINAIS}

O presente trabalho foi desenvolvido na bacia hidrográfica do Rio Gorutuba, no município de Francisco-Sá - MG, com o objetivo de analisar o estado de conservação e preservação de uma porção da área da referida bacia hidrográfica, localizada especificamente no terço superior do seu curso d'água principal.

Os resultados obtidos permitiram inferir as seguintes considerações:

$\mathrm{Na}$ área da nascente foi observado que a cobertura vegetal ainda se encontra em bom estado de preservação, devido, provavelmente, a sua localização isolada-e ao difícil acesso ao local. Por outro lado, nas proximidades da nascente já se encontra algumas evidências de degradação do ambiente, como desmatamento e queimadas e a substituição da vegetação nativa por monoculturas de eucaliptos.

Constatou-se que a poluição das águas ao longo do curso principal da bacia hidrográfica se origina basicamente do esgoto doméstico e sanitário que são lançados diretamente no mesmo, sem nenhum tratamento. Pode-se observar, também, a ocorrência do processo de degradação da mata ciliar ao longo da margem do Rio Gorutuba, que está sendo substituída por áreas de pastagens, áreas agricultáveis e áreas com o cultivo de monoculturas, que, consequentemente, afetam a qualidade e a disponibilidade hídrica do curso d'água principal.

Quanto ao processo de erosão das encostas e de assoreamento do curso principal da bacia hidrográfica, pode-se dizer que este se encontra em níveis avançados e o que influencia esse processo é a degradação da mata ciliar e as práticas antropogênicas relacionadas principalmente às atividades de exploração da agricultura e da pecuária presente em suas margens.

Diante do exposto, prospecta-se que a área de estudo requer mais atenção no que concerne à preservação e conservação dos recursos naturais e que as medidas necessárias a serem tomadas devem ser adequadas à atual situação de degradação; e estas, por sua vez, deverão ser realizadas com a participação da população e dos poderes públicos municipais e estaduais presentes na área da bacia hidrográfica, com vistas à minimização dos problemas ambientais constatados. Pode-se afirmar, também, que a população carece de campanhas de educação ambiental, que tenham como objetivo mostrar a importância social e econômica dos 
recursos hídricos presentes na área, e assim sensibilizá-la para que possam mudar seus hábitos e atitudes em relação aos problemas ambientais existentes na área e até mesmo exercerem com mais ênfase seus direitos, em termos cobrança e/ou reivindicação juntos às autoridades competentes, com vistas à implementação de políticas públicas de preservação e conservação dos recursos naturais no contexto da bacia hidrográfica, como um todo.

\section{REFERÊNCIAS}

ARAUJO, G. H. de S.; ALMEIDA, J. R. de, 1950-; GUERRA, A. J. T. Gestão ambiental de áreas degradada. Rio de Janeiro: Bertrand Brasil, 2005. 320p.

BRAGA, Benedito. et al Monitoramento de quantidade e qualidade das águas. In:

REBOUÇAS, A.C.; BRAGA, B.; TUNDISI, J. G. Águas Doces no Brasil: capital ecológico, uso e conservação. (org) 3ª . Ed. São Paulo: Escrituras Editora, 145 - 160, 2006.

CASTRO, D. de; MELLO, R. S. P.; POESTER, G. C. Práticas para restauração da mata ciliar. Porto Alegre : Catarse - Coletivo de Comunicação, 2012.

CHAVES, A. Importância da mata ciliar (legislação) na proteção dos cursos hídricos, alternativas para sua viabilização em pequenas propriedades rurais. Passo Fundo. 2009.

IBGE. INSTITUTO BRASILEIRO DE GEOGRAFIA E ESTATÍSTICA. Divisão regional do Brasil em mesorregiões e microrregiões geográficas. Volume 1. Rio de Janeiro: IBGE, 1990.

LIMA, W. de P. Hidrologia florestal aplicada ao Manejo de bacias hidrográficas. $2^{\mathrm{a}}$ Ed. Piracicaba. 2008. 253 p.

LINO, C. F.; DIAS, H. Águas da Mata Atlântica Programa Água e Florestas da Mata Atlântica. São Paulo, 2005, 76 p.

MACHADO, C. J. S.; FERREIRA, J. A.; RITTER, E. A Poluição das Águas Doces: Integrando a Gestão dos Resíduos Sólidos na Gestão dos Recursos Hídricos. In:MACHADO, C. J. S. Gestão de águas doces. Rio de Janeiro: Interciência, 2004.

MENDES, C. A.Técnicas de análise ambiental. In: Avaliação ambiental integrada de bacia hidrográfica / Ministério do Meio Ambiente / SQA. - Brasília: MMA, 2006. Disponível em $<$ http://www.mma.gov.br/estruturas/sqa_pnla/_arquivos/sqa_3.pdf $>>$.

Acesso em 10/06/2015.

MENDONÇA, F. de A. e LEITÃO, S. A. M. Riscos e vulnerabilidade socioambiental urbana: uma perspectiva a partir dos recursos hídricos. IN: GeoTextos, vol. 4, n. 1 e 2, 2008. 145-163. Disponível 
em<<http://www.portalseer.ufba.br/index.php/geotextos/article/viewFile/3300/2413>>. Acesso em 10/06/2015.

MORAES, D. S. L.; JORDÂO, B. Q. Degradação de recursos hídricos e seus efeitos sobre a saúde humana. In: Revista de saúde pública 2002; 36(3): 370-4. Disponível em http://www.rsp.fsp.usp.br/ . Acesso em 15/01/2015.

NUNES, W. A. G. de A. Efeitos da Irrigação com água de poços tubulares e do Rio Gorutuba sobre propriedades de solos da região de Janaúba- MG. - Viçosa: UFV, 2003. 167. : il. Disponível em

<<http://alexandria.cpd.ufv.br:8000/teses/solos\%20e\%20nutricao\%20de\%20plantas/2003/179817f.pdf > Acesso em 15/06/2015.

OLIVEIRA, M. E. de. e SILVA, I. L. da. Efeitos do fogo sobre o solo.In: Floresta e Ambiente. 1994. Disponível em $\ll$

http://www.floram.org/files/v1n\%C3\%BAnico/v1nunicoa19.pdf >>. Acesso em 10/06/2015. ORTEGA, D. J. P. Avaliação dos efeitos das atividades antrópicas na bacia hidrográfica do Córrego do Ipê, município de Ilha Solteira - SP. Ilha Solteira: [s.n.], 2011. 151 f. : il.

PIRES, J. S. R.; SANTOS, J. E.; DEL PRETTE, M. E. A utilização do conceito de Bacia Hidrográfica para a Conservação dos Recursos Naturais. In: SCHIAVETTI, A.; CAMARGO, A. F. M. Conceitos de bacias hidrográficas: teorias e aplicações. - Ilhéus, Ba: Editus, 2005. 293p. : Il.

PEREIRA, R. S. Identificação e caracterização das fontes de poluição em sistemas hídricos. In: Revista Eletrônica de recursos Hídricos. IPH- UFRGS. v.1, n. 1. p. 20-36, 2004. Disponível em <<http://www.abrh.org.br/informacoes/rerh.pdf 〉> Acesso em 10/06/2015.

SANTOS, G. V.; DIAS, H. C. T.; SILVA, A. P. de S.; MACEDO, M. de N. C. Análise hidrológica e socioambiental da bacia hidrográfica do córrego Romão dos Reis, ViçosaMG. Revista Árvore (Online), v. 31, n. 5, 2007. Disponível em: Acesso em:16/06/2015.

SETTI, A. A.; LIMA, J. E. F. W.; CHAVES, A. G. de M.; PEREIRA, I. de C. Introdução ao gerenciamento de recursos hídricos. Brasília. $2^{\mathrm{a}}$ ed. - Agência Nacional de Energia Elétrica, Superintendência de Estudos e Informações Hidrológicas, 2000. 207 p.:il.; 23 cm.

SILVA, A. M.; SCHULZ, H. E. ; CAMARGO, P. B. Erosão e Hidrossedimentologia em Bacias Hidrográficas. São Paulo: Rima, 2003, 2004.

SOUZA, A. C. M.; SILVA, M. R. F. da.; DIAS,N. da S. Gestão de recursos hídricos: o caso da bacia hidrográfica Apodi/Mossoró (RN).In: Revista Irriga.Botucatu:Edição Especial, p. $280-2962012$.

ZOCCAL, J. C.Soluções cadernos de estudos em conservação do solo e água. Presidente Prudente: CODASP, 2007, v. 1, n.1, mai. 2007. Disponível em $<<$ http://www.cecs.unimontes.br/index.php/pt/banco-de-dados/diagnosticos-eestudos/recuperacao-de-areas-degradadas/livros-cartilhas-e-boletins.html $\gg$. Acesso em $11 / 06 / 2015$ 
Maria Tereza Pereira dos Santos - Possui Graduação em Geografia pela Universidade Estadual de Montes Claros (UNIMONTES). Atualmente está vinculada como bolsista BAT II, no projeto de pesquisa Extrativismo do Pequi em Minas Gerais: Potencial Produtivo, Aspectos Culturais e Ambientais, Socioeconomia e Organização Comunitária, desde de Novembro de 2015.

Expedito José Ferreira - Possui Graduação em Agronomia, Mestrado e Doutorado em Engenharia Agrícola, todos cursados pela Universidade Federal de Viçosa (UFV). Atualmente é Professor do Programa de Mestrado em Geografia da Universidade Estadual de Montes Claros (PPGEO/UNIMONTES).

Maykon Fredson Freitas Ferreira - Possui Graduação e Mestrado em Geografia, ambos cursados pela Universidade Estadual de Montes Claros (UNIMONTES). Atualmente é integrante do Núcleo de Estudos Sismológicos da Universidade Estadual de Montes Claros (NES/UNIMONTES).

Artigo recebido em: 30 de março de 2017.

Artigo aceito em: 06 de junho de 2017. 